\title{
USE OF DOPPLER SODAR IN ATMOSPHERIC MEASUREMENTS
}

Edmilson Dias de Freitas, Maria Assunção Faus da Silva Dias, K. Narayanan Nair and Pedro Leite da Silva Dias

Department of Atmospheric Sciences

University of São Paulo - São Paulo - Brazil*

\section{RESUMO}

O uso do Sodar Doppler tem trazido avanços significativos ao entendimento dos processos de camada limite atmosférica. Estes instrumentos têm demonstrado suas habilidades em um grande número de estudos, tais como circulações de brisa marítima/terrestre, escoamento em terrenos complexos, ondas de gravidade, jatos de baixos níveis e sistemas frontais, além de possibilitar estimativas quantitativas de parâmetros de turbulência tais como fluxo de calor sensível, balanço de energia cinética turbulenta, função estrutura de temperatura e a determinação da altura da camada de mistura.

\footnotetext{
* Corresponding authors address:

Instituto Astronômico e Geofísico / USP

Rua do matão 1226 - Cidade Universitária - São Paulo - SP

CEP 05508-900
} 
Neste trabalho, o princípio de funcionamento de diferentes tipos de Sodar, suas habilidades e limitações na instalação desses instrumentos são apresentados. No final, alguns fenômenos detectados por um Sodar Doppler do tipo "phased-array", recentemente adquirido pelo IAG-USP, são apresentados.

\section{INTRODUCTION}

Over the past three decades, the use of Doppler Sodars has led to significant advances in our understanding of the atmospheric boundary layer ( $A B L)$. These instruments have demonstrated, versatility in several applications, such as land/sea breeze circulation, wind flow in complex terrains (Kalogiros et. al., 1999), gravity waves, frontal systems (Ralph et. al., 1993) and low-level jet (Patra et. al., 1998; Nair, 1999). In addition they are suitable to derive turbulence parameters such as the turbulent kinetic energy, temperature structure function (Singal et. al., 1982), sensible heat flux, velocity structure parameter, and determining mixed layer height (Kalogiros et. al., 1999).

There are two basic arrangements used by sodars: monostatic and bistatic. A monostatic sodar system consists of a collocated transmitter and receiver. In most cases, the transmitter and receiver are combined into a single transceiver antenna. A bistatic system consists of a separated transmitter and receiver. The distance of separation varies from 100 to $300 \mathrm{~m}$. In the specific case of monostatic system, the determination of total wind vector requires a minimum of three transmitter-receiver combinations (Threeaxis monostatic Doppler Sodar) with a difference in the orientation of the antennas. Figure 1 shows a schematic of this type of Doppler sodar. Figure 2 shows the schematic of a bistatic sodar.

154 Rev. Ciência e Natura, Dispersion Process: 153 - 165 , 2000. 


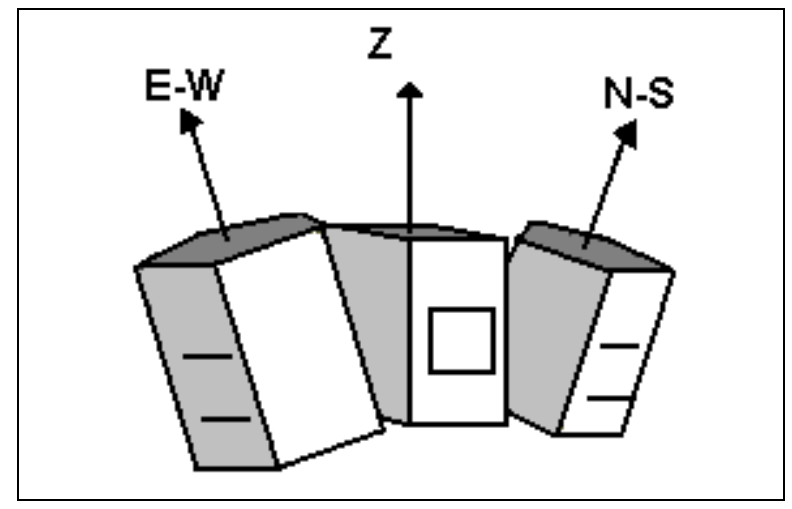

Fig 1: Schematic of a three-axis monostatic Doppler sodar.

Both arrangements have advantages and disadvantages. Monostatic systems do not require too much space, whereas bistatic sodars require large areas of land since the baseline between transmitter and receiver varies from 100 to $300 \mathrm{~m}$.

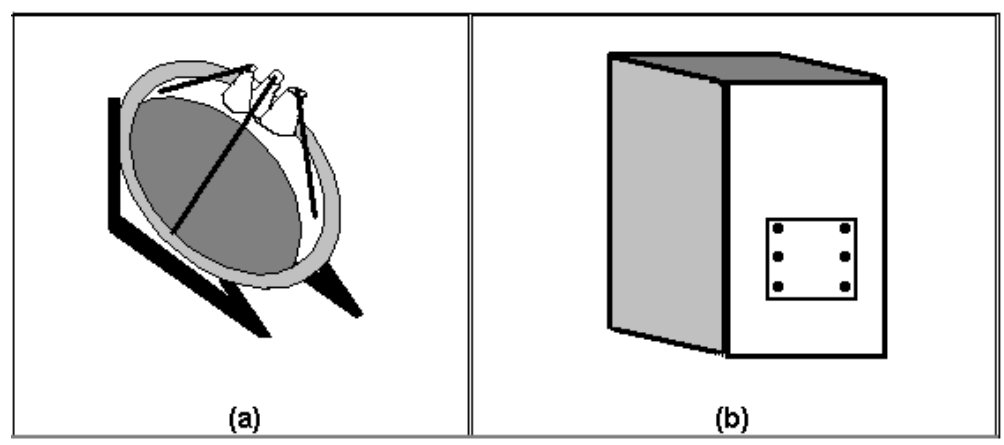

Fig 2: Schematic of a bistatic sodar system with separated transmitter and receiver antennas. (a) tansmitter antenna and (b) transmitter/receiver antenna.

Rev. Ciência e Natura, Dispersion Process: 153 - 165 , 2000. 
Monostatic sodars must rely solely on the existence of temperature inhomogeneities to backscatter the acoustic signal, whereas bistatic systems are able to receive signals that are scattered by thermal and mechanical turbulence. This happens due to angular dependence of the scattering of sound waves by the atmosphere. Figure 3 shows this dependence.

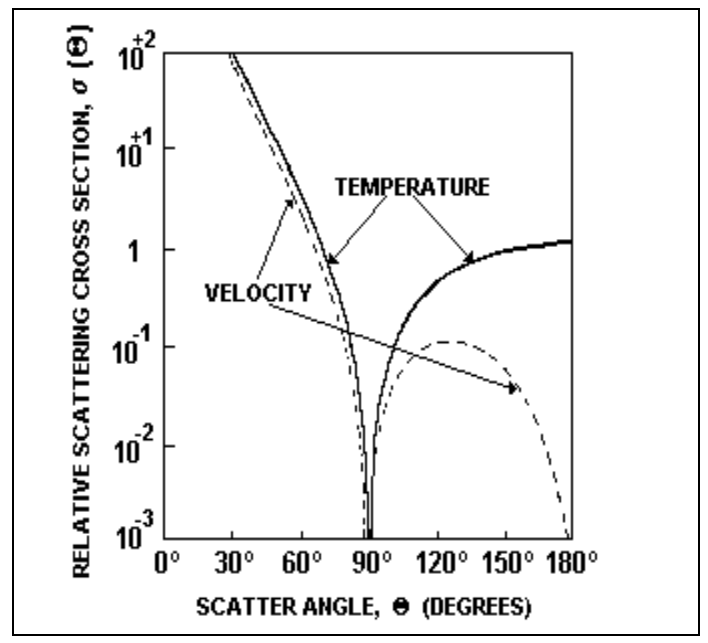

Fig 3: Angular dependence of the Scattering of sound waves by the atmosphere.

A modified version of the three-axis monostatic system is the phased array Doppler Sodar. Instead of using three antenna dishes that are 1$2 \mathrm{~m}$ in diameter, an array of vertically pointing transceivers is utilized. Each transceiver measures approximately $10 \mathrm{~cm}$ in diameter. [case of Remtech's Doppler Sodar model PA2 (DT 94/003) which uses Motorola type 1025 tweeters]. The total number of transceivers varies from 20 to 200 . These transceivers are sequenced slightly out of phase electronically to steer the 156 Rev. Ciência e Natura, Dispersion Process: 153 - 165 , 2000. 
acoustic beam at angles from the vertical. Thus, a phased-array sodar essentially mimics the acoustic beam pattern produced by a three-axis monostatic system. Figure 4 shows a photograph of this system.

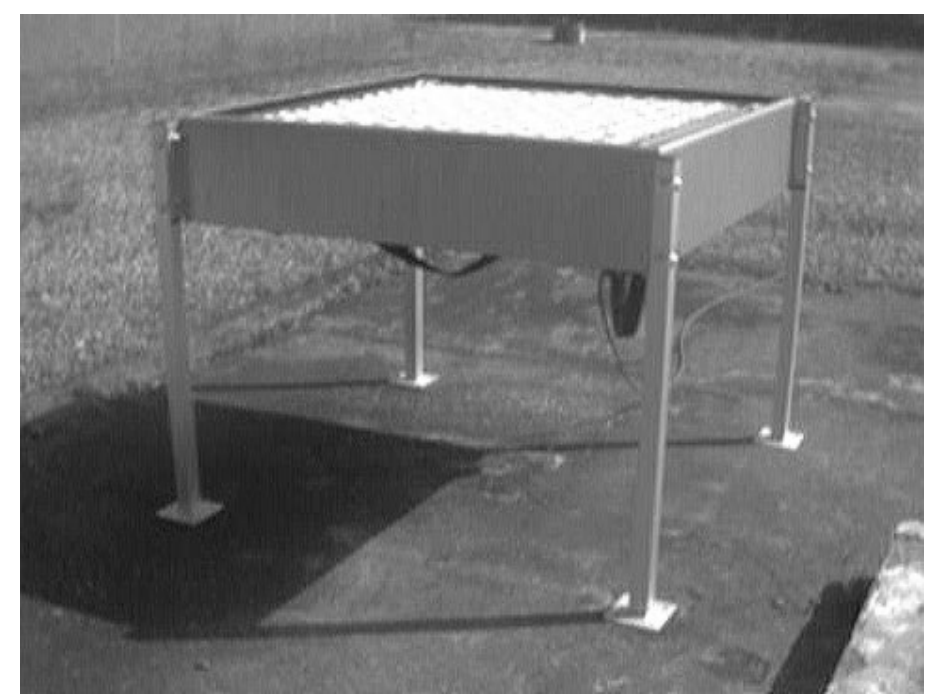

Fig 4: phased-array Doppler Sodar (Remtech - PA2 model).

\section{OPERATION}

The sodar operates on the principle of acoustic backscattering. Acoustic transducers are used in order to generate acoustics pulses that are directed into the atmosphere or downward into a parabolic dish which transmits the acoustic pulse. The frequency of these pulses varies between 1000 and $4500 \mathrm{~Hz}$, which corresponds to wavelengths from 34 to $8 \mathrm{~cm}$, respectively. The pulse width $\tau$ may vary between 50 and 300 ms with peak power output ranging from 2 to $300 \mathrm{~W}$. 
When sound waves propagate through the atmosphere, a small fraction of their energy is scattered by small-scale $(10-30 \mathrm{~cm})$ temperature inhomogeneities whose scale size is half wavelength of the acoustic pulse. These inhomogeneities are produced by turbulence in regions with large-scale potential temperature gradients, layers of wind shear or thermal plumes produced by surface heating.

The first information extracted from the measurements is the effective intensity of the backscattered signal. In the case of Remtech's Doppler Sodar model PA2, there is a system that subtracts the ambient noise of the information received by the antenna, retaining the returned echo only (Learning mode). The power of the backscattered signal is proportional to the temperature structure function, $C_{T}{ }^{2}$, which is a measure of the intensity of the small-scale air temperature fluctuations at the probing heigth. This is important because $C_{T}^{2}$ has large values and repeated patterns. This is true mainly during radiation inversions, within elevated inversion layers, at the periphery of convective columns or thermals, in the sea/land breeze frontal surface and in a general way at the boundary between masses of air of different temperatures. Assuming a homogeneous atmosphere, with isotropic turbulence, and within the Kolmogorov inertial subrange, the scattered power per unit volume per unit incident flux per unit solid angle in dry air (Little, 1969) is given by:

$$
\sigma\left(\theta_{s}\right)=0.03 k^{1 / 3} \cos ^{2} \theta_{s}\left(\frac{C_{v}^{2}}{C_{s}^{2}} \cos ^{2} \frac{\theta_{s}}{2}+0.13 \frac{C_{T}^{2}}{T^{2}}\right)\left(\operatorname{sen} \frac{\theta_{s}}{2}\right)^{-11 / 3}
$$

where $\theta_{s}$ is the scattered angle from the initial direction of the acoustic beam propagation, $\boldsymbol{k}$ is the acoustic wavenumber, $\boldsymbol{C}_{\boldsymbol{s}}$ is the sound speed and $\boldsymbol{T}$ is the ambient air temperature. The temperature and velocity structure functions are defined, respectively, as 


$$
\begin{aligned}
& C_{V}^{2}=\left[\frac{V(z)-V(z+\Delta z)}{\Delta z^{1 / 3}}\right]^{2} \\
& C_{T}^{2}=\left[\frac{T(z)-T(z+\Delta z)}{\Delta z^{1 / 3}}\right]^{2}
\end{aligned}
$$

The second information obtained by sodar is the difference between the transmitted frequency, $f$ and the backscattered Doppler shifted frequency, $f_{s}$, the Doppler shift, which is directly proportional to the radial wind velocity along the acoustic beam axis. The radial velocity $V_{r}$ along the axis is given by

$$
V_{r}=-\frac{C_{s}}{2}\left(\frac{f_{s}}{f}-1\right)
$$

The vector winds $\mathrm{u}$ (zonal, with westerly as positive), $\mathrm{v}$ (meridional, with southerly as positive) and $w$ (vertical, with up drafts as positive) are computed from the standard Doppler equation

$$
V \cos \theta=\frac{C_{s}}{2 \sin \frac{\theta_{s}}{2}} \frac{\Delta f}{f}
$$

where $\mathrm{V}$ is the Doppler speed along the probing direction and $\Delta f=f-f_{s}$ is the Doppler shift.

In the monostatic mode $\theta=180^{\circ}$ and the equation reduces to

$$
\frac{\Delta f}{f}=-\frac{2 V}{C_{s}}
$$

If $\alpha$ is the beaming axis with the vertical we have

$$
\mathrm{u}=\mathrm{V}_{1} \cos \alpha, \mathrm{v}=\mathrm{V}_{2} \cos \alpha \text { and } \mathrm{w}=\mathrm{V}_{3}
$$

where $V_{1}, V_{2}$ and $V_{3}$ are the Doppler derived speeds along east-west, northsouth and vertical directions. Making use of mathematical coordinate Rev. Ciência e Natura, Dispersion Process: 153 - 165 , 2000. 
transformation in $\mathrm{u}, \mathrm{v}$ and $\mathrm{w}$, the horizontal wind speed $(\mathrm{U})$ and direction $(\phi)$ and vertical wind speed $(\mathrm{w})$ are computed.

In the monostatic system the scattering angle is $180^{\circ}$. Thus, (1)

reduces to

$$
\sigma(180)=0.0039 k^{1 / 3} \frac{C_{T}^{2}}{T^{2}}
$$

That is to say that, the intensity of the backscattered signal depends only on the thermal structure of the atmosphere.

Nair et al. (1989) presented an expression to the power of backscattered signal as:

$$
P_{r}=P_{t}\left(\frac{C_{s} \tau}{2}\right) \sigma(180) A_{r} \frac{B}{R^{2}} \exp (-2 \alpha R)
$$

where $A_{r}$ is the collecting area of the acoustic antenna, R is the range of the scattering region, $\alpha$ is the attenuation coefficient and $B$ includes both the beam shape compensation factor and the antenna efficiency.

\section{EXPOSITION}

The backscattered signal can be polluted by different spurious sources such as:

- electrical influences: poor grounding which may generates higher harmonics of $50 / 60 \mathrm{~Hz}$;

- magnetic influences: due to the proximity of transformers and power lines;

- acoustic influences: air conditioner fans which radiate acoustic energy.

The Sodar is sensitive to fixed echoes due to spurious reflections of the land, buildings, trees, meteorological towers, through the secondary lobes as seen in Figure 5. Although the secondary lobes parallel 
to surface are very low due to the antenna design, compared to the main lobe, fixed echoes can be of the same order or more than the actual signal. This is due to the fact that the capacity of signal return by the atmosphere is very low compared to the returns from rigid obstacles. In Remtech PA-2 system, there is provision for suppressing fixed echo from the intensity of backscattered radiation.

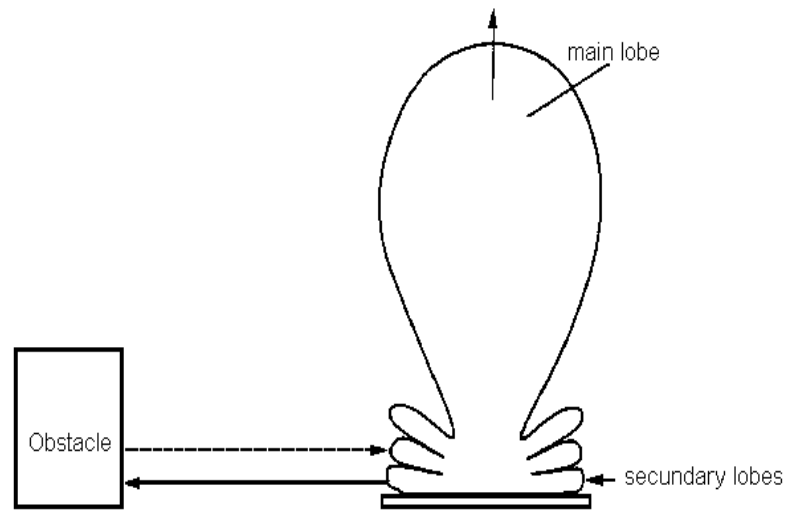

Fig 5: Illustration of echoes generated by fixes obstacles.

\section{SOME CASE STUDIES USING REMTECH'S DOPPLER SODAR DATA}

One of the valuable information this instrument provides, is the inversion height of the $A B L, Z_{i}$. Figure 6 shows the time evolution for this parameter from 0700 local time 07 Aug to 0700 local time 08 Aug 1999. The data were observed in São Paulo, Brazil, during a field campaign for studying the meteorological conditions associated with air pollution. $Z_{i}$ reaches a maximum value near 1700 local time. Between 20 to $22 \mathrm{hrs} Z_{i}$ attains the minimum value. As it will be shown later, this decrease was mostly associated with the passage of a cold frontal system over São Paulo at that time, 
besides night time surface based inversion. The relatively low values for the inversion height inhibit vertical transfer of pollutants.

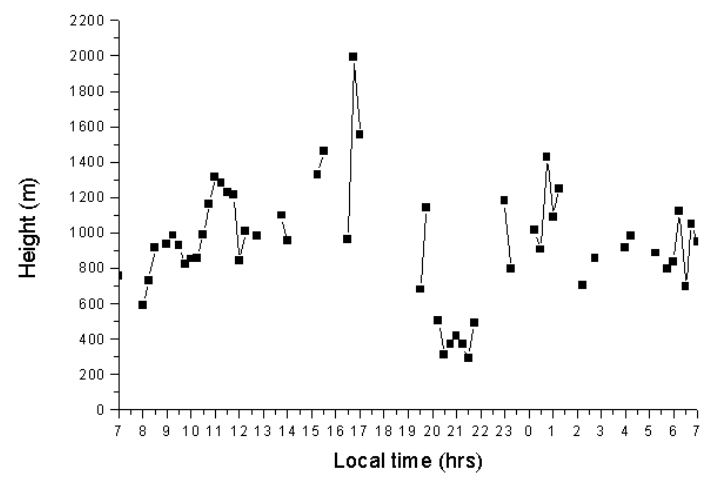

Fig 6: Time evolution of the inversion height $\left(Z_{i}\right)$ from 07 Aug to 08 Aug 1999.

Another capability of this system is it ability to provide vector wind profiles, with very good height and time resolutions. Figure 7 shows the time evolution of the wind for 07 Aug to 08 Aug 1999 in São Paulo. At the beginning of the period, up to $400 \mathrm{~m}$ height, the predominant wind direction was from northeast, indicating a typical synoptic condition before the arrival of the frontal system. After this, the wind direction changed to northwesterly during the passage of the system at about $20 \mathrm{hrs}$ (LT) to southwesterly. There are some gaps in the data due to the high level of ambient noise. At 00:15 (LT), 08 Aug, the presence of a Low Level Jet (LLJ) above $400 \mathrm{~m}$ height is seen, which will be discussed in more detail.

Figure 8 shows the wind speed profile and figure 9 the wind direction profile at 08 Aug 0015 local time. It is possible to see the occurrence 162 Rev. Ciência e Natura, Dispersion Process: 153 - 165 , 2000. 
of LLJ between $400 \mathrm{~m}$ and $500 \mathrm{~m}$, above the stable region. LLJ is characterized by almost constant wind direction with strong wind speeds above $300 \mathrm{~m}$. Acceleration of the LLJ is associated with inhibition of vertical transport of horizontal momentum at $300 \mathrm{~m}$ associated with enhancement of the zonal flow due to intensification of the thermal wind induced by the frontal passage.

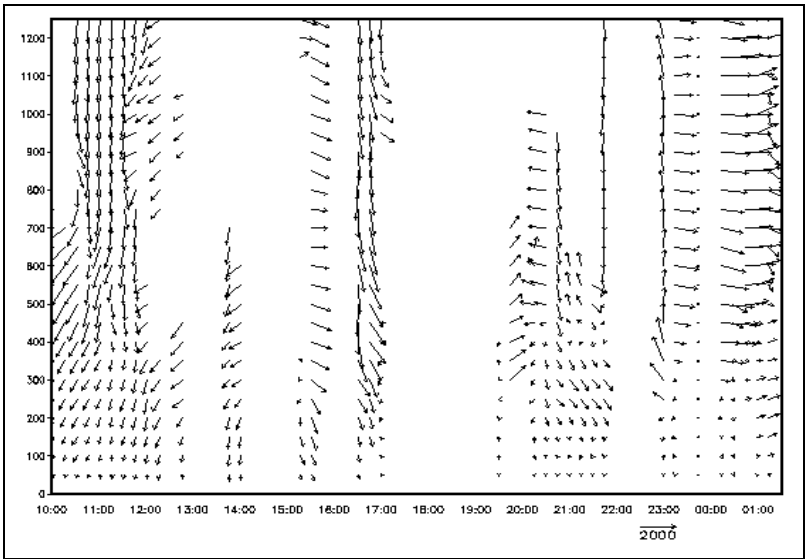

Fig 7: Time evolution of the wind from 07 Aug to 08 Aug 1999.

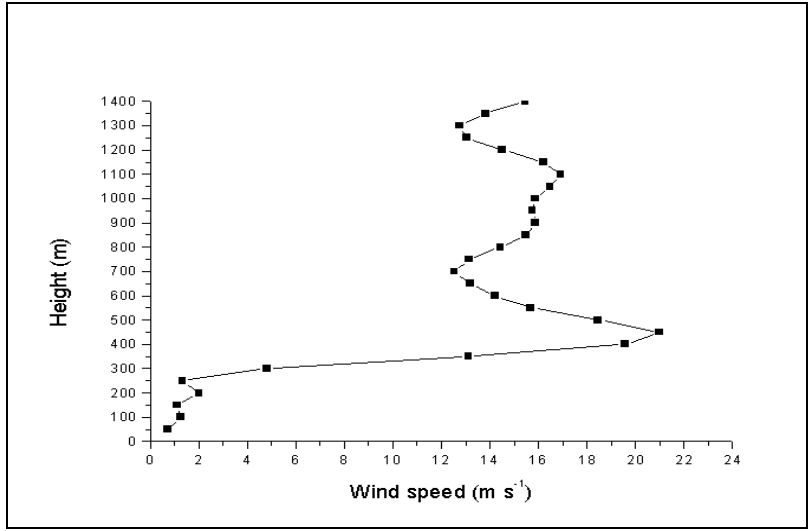

Fig 8: Wind speed at 0015 local time, in 08 Aug 1999, showing the occurrence of LLJ.

Rev. Ciência e Natura, Dispersion Process: 153 - 165 , 2000. 


\section{CONCLUSIONS}

Doppler sodar is seen to be a potential tool to probe the atmospheric processes and are being used for (i) micrometeorology (ii) pollution control (iii) aviation safety and (iv) agricultural meteorology, where information on the depth of boundary layer, layering, flow fields, fluxes of momentum, structure functions, atmospheric stability, entrainment and up drafts are required.

The Remtech Doppler Sodar at IAG, USP, is a phased array version and is capable of (i) suppressing ambient noise in the data (ii) invalidating fixed echoes, (iii) electronic beaming, (iv) multiple frequency operation enhancing signal to noise ratio, (v) multiple coding technique with 1024 point FFT software and (vi) pattern recognition software.

The capabilities of modern sodars in studying micrometeorological processes and providing means to understand the coupling between boundary layer when events like gravity waves, low level jets, sea breeze fronts and cold fronts occurs are proved beyond doubt.

\section{ACKNOWLEDGMENTS}

The authors thank the Fundação de Amparo à Pesquisa do Estado de São Paulo (FAPESP) for financial support during the course of this study. 


\section{REFERENCES}

DT 94/003: Remtech Doppler Sodar Operating Manual. PA1, PA2, PA3 DELL PC compatible based systems.

Kalogiros, J. A., C. G. Helmis, D. N. Asimakopoulos and P. G. Papageorgas, 1999: Estimation fo ABL Parameters Using the Vertical Velocity Measurements of an Acoustic Sounder. Bound.-Layer Meteor. 91, 413449.

Little, C. G., 1969: Acoustic methods for the remote probing of the lower atmosphere. Proc. IEEE, 57, 571-578.

Nair, K. N., P. K. Kunrikrishnan, K. S. Gupta and R. Ramachadran, 1989: Sudy of vertical wind and temperature turbulence in a convective boudary layer from Sodar observation at Thumba. Indian Journal of Radio \& Space Physics, 18, 157-159. , 1999: On Low Level Jet at Coastal Station Thumba. Indian Journal of Radio \& Space Physics, 28, 55-59.

Patra, A. K., U. K De and D. Lohar, 1998: Existence of low level jet during premonsoon period over eastern india and its role in the initiation of nocturnal thunderstorms. Atmósfera. 12, 15-26.

Ralph, F. M., C. Mazaudier, M. Crochet and S. V. Venkateswaran, 1993: Doppler Sodar and Radar Wind-Profiler Observations of Gravity-Wave Activity Associated with a Gravity Current. Mon. Wea. Rev. 121, 444463.

Singal, S. P., B. S. Gera, and S. K. Aggarwal, 1982: Determination of structure parameters using sodar. Bound.-Layer Meteor. 23, 105-114. 
166 Rev. Ciência e Natura, Dispersion Process: 153 - 165 , 2000. 